\title{
Bernhard Streck, Leo Frobenius, Afrikaforscher,
} Ethnologe, Abenteuer

Frankfurt am Main : Societäts-Verlag, 2014, 219 p., 14,80 €

Hélène Ivanoff

\section{OpenEdition}

Journals

Édition électronique

URL : http://journals.openedition.org/ifha/8195

DOI : 10.4000/ifha.8195

ISSN : 2198-8943

Éditeur

IFRA - Institut franco-allemand (sciences historiques et sociales)

Référence électronique

Hélène Ivanoff, « Bernhard Streck, Leo Frobenius, Afrikaforscher, Ethnologe, Abenteuer », Revue de I'IFHA [En ligne], Date de recension, mis en ligne le 14 avril 2015, consulté le 22 septembre 2020. URL : http:// journals.openedition.org/ifha/8195; DOI : https://doi.org/10.4000/ifha.8195

Ce document a été généré automatiquement le 22 septembre 2020

(CIFHA 


\title{
Bernhard Streck, Leo Frobenius, Afrikaforscher, Ethnologe, Abenteuer
}

\author{
Frankfurt am Main : Societäts-Verlag, 2014, 219 p., 14,80€
}

Hélène Ivanoff

\begin{abstract}
À l'occasion de l'anniversaire du centenaire de la création de l'université Goethe de Francfort en 2014 - célébrant les fondateurs, les protecteurs et les savants de cette institution - Bernhard Streck consacre une biographie à l'africaniste, ethnologue et aventurier que fut Leo Frobenius (1873-1938). Cet autodidacte est l'un des pionniers de cette première école de Francfort, qui se fit ensuite connaître à l'étranger à travers les figures de Max Horkheimer (1895-1973) et de Theodor Adorno (1903-1969). Le cercle des antimodernistes regroupait à l'époque le germaniste Max Kommerell (1902-1944), l'historien Ernst Kantorowicz (1895-1963) ou les philologues Karl Reinhardt (1886-1958) et Walter F. Otto (1874-1958). Ce contexte institutionnel explique l'intérêt que suscita, au sein de l'université, le transfert de l'Institut de morphologie culturelle de Munich vers Francfort en 1924, car il apportait dans ces débats un élargissement des horizons au champ non européen. Le maire Ludwig Landmann (1868-1945) vit, quant à lui, l'opportunité pour la ville de s'enrichir des collections ethnographiques rassemblées par Leo Frobenius et de disposer d'une bibliothèque centrée sur l'Afrique, grâce au riche fonds d'archives constitué dès 1894, Afrika Archiv.
\end{abstract}

Après lui avoir consacré plusieurs années de recherches, l'ethnologue Bernhard Streck livre ici un portrait détaillé de cette personnalité originale et polémique du monde académique de Francfort. Il analyse ses nombreuses expériences de terrain en Afrique et ses développements théoriques, montrant comment l'ethnologue fut à l'origine de nouvelles orientations au sein de l'ethnologie allemande ou Völkerkunde. Celles-ci perdirent certes de leur rayonnement sur la discipline à partir des années 1960, mais contribuèrent durablement à construire et à diffuser une nouvelle image l'Afrique, notamment par le biais des écrivains de la «négritude" tel Léopold Sédar Senghor (1906-2001). Le concept fondateur de la morphologie culturelle est celui de Paideuma, souvent traduit par l'«âme de la culture ", et l'émergence d'une anthropologie de la forme, ou Gestaltanthropologie, s'inscrit ainsi dans l'héritage romantique allemand. Elle 
se comprend également dans l'époque de l'après-guerre marquée par la chute de la monarchie des Hohenzollern et la perte des colonies. Le cadre d'une " métaphysique de la désillusion » explique d'une part la fascination de Leo Frobenius pour ce « continent mourant", dont il collecta avec passion les masques, les contes puis les images rupestres, et d'autre part la parenté de sa théorie de la culture avec d'autres écrits philosophiques de l'époque, à savoir ceux du comte Hermann Keyserling (1880-1946) ou d'Oswald Spengler (1880-1936).

Les biographes de Leo Frobenius distinguent volontiers trois périodes dans la vie de Leo Frobenius : celle des premières quêtes et questions de 1894 à 1904, celle du chercheur parti douze fois en expédition en Afrique entre 1904 et 1935 et le temps de la gloire, qui commença au plus tard avec la constitution des archives du folklore à Francfort en 1928. D'après l'auteur, la vision du monde de Leo Frobenius est cependant marquée par une grande continuité et stabilité, perceptible tant chez le jeune ethnologue de 1904, qu'après l'installation à Francfort en 1925 ou lors de l'année quasi-triomphale de 1938, où il s'affirma comme un théoricien de la culture dans le monde universitaire. Il avait alors gagné une notoriété qu'il devait autant à ses écrits qu'à l'énergie dépensée pour réunir des fonds pour ses expéditions, ou qu'à ses apparitions théâtrales sur la scène publique qui lui assurèrent une visibilité auprès des médias de l'époque. L'auteur souligne avec perspicacité les liens entre sa vision de l'Afrique et en particulier du paganisme africain et la vision que le milieu conservateur allemand avait alors de luimême avant et après la Première Guerre mondiale.

B. Streck propose ainsi un parcours en sept étapes. Il part des premiers pas de Leo Frobenius dans le monde des musées ethnologiques et de ses écrits sur les masques des confréries africaines pour révéler son goût pour la mythologie. Il met ensuite en lumière les nouvelles voies ouvertes par le chercheur, en l'occurrence les expériences de terrain en Afrique et les collectes de chants, contes et fables, s'inscrivant dans la tradition de Johann Gottfried Herder (1744-1803). Ces recherches ne pouvaient que susciter l'intérêt des philologues de l'université de Francfort, comme Walter F. Otto (1874-1958). Elles furent suivies de la collecte d'images, avec l'établissement de relevés d'art rupestre africain. Leo Frobenius se présenta alors comme un interprète de la diversité des formes culturelles, notamment dans son œuvre la plus connue, parue en 1933, « Histoire de la civilisation africaine » ou Kulturgeschichte Afrikas.

Dans un quatrième temps, l'auteur présente la théorie de la culture, notamment à partir des premiers écrits programmatiques, comme Paideuma en 1921 et Schicksalkunde en 1932, où Leo Frobenius évoque aussi le déclin de la culture allemande par la disparition du sentiment de la vie et espère la régénérescence de l'Allemagne. Analysant la relation établie avec Guillaume II dès 1912, B. Streck explique alors les rapports de cette théorie de la culture au monarchisme et au nationalisme, et à ce qu'Hugo von Hofmannstahl (1874-1929) dénomma la "révolution conservatrice", diffusée par le cercle constitué autour de Stefan George (1868-1933). Il est ainsi possible de mieux saisir l' «expressionnisme » ethnologique de Leo Frobenius, selon la formule pertinemment choisie par B. Streck, en raison du caractère excentrique et pathétique de sa pensée. De sa résistance au réalisme, au rationalisme et au matérialisme des sociétés européennes vient son admiration pour la spiritualité, le mysticisme et l'émotion qui caractérisent selon lui la culture de l'Afrique. Dans le dernier chapitre, B. Streck évalue enfin la portée et l'actualité des théories de Leo Frobenius suite à la reconstruction de l'Institut de morphologie culturelle après-guerre, qui expliquent 
pourquoi Frobenius a toute sa place dans la galerie des ancêtres des universités allemandes.

Et c'est en cela que réside le mérite de cette biographie de Leo Frobenius, car elle replace effectivement les théories de l'ethnologue dans les courants de pensées de son époque, et permet ainsi d'éclairer les motivations profondes de l'intégration de son institut de recherche à l'université de Francfort. La précédente biographie de HansJürgen Heinrichs en 1999 avait laissé en partie ces aspects dans l'ombre. Tout en étant d'une grande précision sur les données biographiques, l'ouvrage de B. Streck apporte dès lors une analyse très attendue de sa pensée, dont il est incontestablement l'un des meilleurs spécialistes. Il met aussi en lumière l'histoire de l'Institut de morphologie culturelle, qui prit le nom de Frobenius-Institut après 1945, poursuivant les voies ouvertes par l'ethnologue, et qui se trouve aujourd'hui à la tête de la plus importante collection mondiale de relevés d'art rupestre africain, mais aussi européen et océanien.

INDEX

Index chronologique : Époque contemporaine

Thèmes : Histoire de la culture, Histoire des mentalités, Histoire de l'art

\section{AUTEUR}

HÉLĖNE IVANOFF

Centre Georg Simmel, CNRS-UMR 8131, EHESS 